\title{
Mapping theme trends and recognizing hot spots in postmenopausal osteoporosis research: a bibliometric analysis
}

\author{
Siming Zhou Equal first author, 1, Zhengbo Tao ${ }^{\text {Equal first author, 1 }}$, Yue Zhu ${ }^{\text {Corresp., } 1}$, Lin Tao ${ }^{\text {Corresp. } 1}$ \\ ${ }^{1}$ Department of Orthopaedics, First Hospital of China Medical University, Shenyang, Liaoning, China \\ Corresponding Authors: Yue Zhu, Lin Tao \\ Email address: zhuyuedr@163.com, taolindr@163.com
}

Background: This study aimed to draw a series of scientific maps to quantitatively and qualitatively evaluate hot spots and trends in postmenopausal osteoporosis research using bibliometric analysis.

Methods: Scientific papers published on postmenopausal osteoporosis were extracted from the Web of Science Core Collection and PubMed database. Extracted information was analyzed quantitatively with bibliometric analysis by CiteSpace, the Online Analysis Platform of Literature Metrology and Bibliographic Item Co-Occurrence Matrix Builder (BICOMB). To explore the hot spots in this field, co-word biclustering analysis was conducted by gCLUTO based on the major MeSH terms/MeSH subheading terms-source literatures matrix.

Results: We identified that a total of 5,247 publications related to postmenopausal osteoporosis were published between 2013 and 2017. The overall trend decreased from 1,071 literatures in 2013 to 1,048 literatures in 2017. Osteoporosis International is the leading journal in the field of postmenopausal osteoporosis research, both in terms of impact factor score (3.819) and H-index value (157). The United States has retained a top position and has exerted a pivotal influence in this field. The University of California, San Francisco was identified as a leading institution for research collaboration, and Professors Reginster and Kanis have made great achievements in this area. Eight research hot spots were identified.

Conclusions: Our study found that in the past few years, the etiology and drug treatment of postmenopausal osteoporosis have been research hot spots. They provide a basis for the study of the pathogenesis of osteoporosis and guidelines for the drug treatment of osteoporosis. 


\section{Mapping theme trends and recognizing hot spots in}

2 postmenopausal osteoporosis research: a bibliometric

\section{3 analysis}

4

5

6

7

8

9

10

11

Siming Zhou ${ }^{1 \#}$, Zhengbo Tao ${ }^{1 \#}$, Yue Zhu ${ }^{1}$, Lin Tao ${ }^{1}$

${ }^{1}$ Department of Orthopaedics, First Hospital of China Medical University, Shenyang, Liaoning, China

\#These authors contributed equally to this work

Corresponding Author:

Yue Zhu ${ }^{1}$, Lin Tao ${ }^{1}$

Shenyang, Liaoning, China

Email address: zhuyuedr@163.com; taolindr@,163.com

\section{Abstract}

Background: This study aimed to draw a series of scientific maps to quantitatively and qualitatively evaluate hot spots and trends in postmenopausal osteoporosis research using bibliometric analysis.

Methods: Scientific papers published on postmenopausal osteoporosis were extracted from the Web of Science Core Collection and PubMed database. Extracted information was analyzed quantitatively with bibliometric analysis by CiteSpace, the Online Analysis Platform of Literature Metrology and Bibliographic Item Co-Occurrence Matrix Builder (BICOMB). To explore the hot spots in this field, co-word biclustering analysis was conducted by gCLUTO based on the major MeSH terms/MeSH subheading terms-source literatures matrix.

Results: We identified that a total of 5,247 publications related to postmenopausal osteoporosis were published between 2013 and 2017. The overall trend decreased from 1,071 literatures in 2013 to 1,048 literatures in 2017. Osteoporosis International is the leading journal in the field of postmenopausal osteoporosis research, both in terms of impact factor score (3.819) and H-index value (157). The United States has retained a top position and has exerted a pivotal influence in this field. The University of California, San Francisco was identified as a leading institution for research collaboration, and Professors Reginster and Kanis have made great achievements in this area. Eight research hot spots were identified.

Conclusions: Our study found that in the past few years, the etiology and drug treatment of postmenopausal osteoporosis have been research hot spots. They provide a basis for the study of the pathogenesis of osteoporosis and guidelines for the drug treatment of osteoporosis. 


\section{Introduction}

42 Osteoporosis, described as the microstructural degeneration of bone tissue and low bone mass, is 43 a systemic skeletal disease causing incremental bone fragility and sensitivity to fracture. There is getting fractures as men, making postmenopausal osteoporosis, which results from estrogen deficiency and leads to an increase in bone turnover, one of the most important types of primary osteoporosis. To repair micro-damage and adapt to mechanical and metabolic needs, bone is being continuously remodeled. The remodeling of bone is performed by two specialized cells: bone-forming osteoblasts and bone-resorbing osteoclasts (Wu et al. 2015). Additionally, the loss of connectivity in trabecular bone, and cortical bone thinning and loss of porosity are affected by an imbalance between bone formation and resorption. The existing treatment of osteoporosis is mainly drug-based. Diphosphonates are given as a first-line treatment, followed by denosumab (a RANKL inhibitor). Teriparatide (a fragment of parathyroid hormone) is the only approved anabolic agent. Estrogen replacement therapy or selective estrogen receptor modulators can be considered in specific conditions (McClung et al. 2005). The prevention of osteoporosis focuses on gaining maximum peak bone mass and minimizing postmenopausal and age-related bone loss through nutrition, maintenance of a normal body mass index, regular physical activity, and the absence of smoking (Oncken et al. 2006). By reducing falls in high-risk populations, fractures, the main complication of osteoporosis, may also be restrained (Schwartz et al. 2005).

In recent years, the bibliometric method used most often has been a quantitative analysis, which uses the statistical index to measure the contribution of a subject or scientific publications in an area of research, and shows widely-applied research trends and hot spots. While this method works to a certain extent, different scholars in this field have different results and views, and there is a lack of recent bibliometric research. French bibliometric scientists Callon et al. first presented the co-word analysis in 1986, which was utilized to find information and recognize hot spots in scholarly literature (Hong et al. 2016). To further summarize the focus of the research and structure of the subject by statistical analyses, such as factor analysis, cluster analysis, multivariate analysis or multidimensional scaling analysis, the significant keywords of a theme were categorized. Among these methods, cluster analysis has been widely used to extract a research theme area. Unlike conventional clustering, biclustering permits coinstantaneous cluster rows and columns of matrices, not just the global information, in order to efficiently detect local messages in high-dimensional data. The field of bibliometrics has recommended biclustering analysis in more recent years. Fiannaca et al. revealed miRNA expression profiles in breast cancer using biclustering (Fiannaca et al. 2015), and Li et al. applied biclustering to probe into subject areas and hot spots of research on Internet health information seeking behavior (Zheng et al. 2015). Their research findings suggested that the biclustering method can direct central research focus and the representative literature or research. 
78

79

80

81

82

83

84

85

86

87

88

89

90

91

92

93

94

95

96

97

98

99

100

101

102

103

104

105

106

107

108

109

110

111

112

113

114

115

116

There have been few bibliometric studies on postmenopausal osteoporosis, and those few paid more attention to studying published information than future research trends (Biglu et al. 2014; Pluskiewicz et al. 2018). In this study, an integrated analysis on the external features and content patterns of pertinent literature was performed to clarify the status and progress of postmenopausal osteoporosis research in the past five years. Particularly, co-word biclustering analysis was used to confirm the research hot spots for postmenopausal osteoporosis. We hope that this research will provide some basis for future studies on postmenopausal osteoporosis.

\section{Materials \& Methods}

\section{Data source and search strategy}

Literatures were retrieved online through the Social Science Citation Index and the Science Citation Index-Expanded of the Web of Science Core Collection (WoSCC) on September 7, 2019. The search strategy was used for the following terms with a timeframe of the January 1 , 2013 solstice to December 31, 2017: Osteoporosis, Postmenopausal AND Language = English, and only original articles and reviews were included. Related data were extracted and downloaded without the restriction of language from PubMed, developed by the National Center for Biotechnology Information (NCBI) of the National Library of Medicine (NLM), providing free access to MEDLINE, OLDMEDLINE, and other related databases. MeSH (Medical Subject Headings) terms are a series of standardized words that can map the content of literatures. According to the MeSH words used, co-word clustering analysis can be carried out continuously (Li et al. 2015). The search strategy applied was "Osteoporosis, Postmenopausal"[Mesh]. Publication date was set from Jan 1st, 2013- Dec 31st, 2017.

All of the literature retrieval and download recording were completed in the same day in order to reduce the quantity of citations resulting from frequent database updates.

\section{Data collection}

Two investigators (Siming Zhou and Zhengbo Tao) independently conducted the primary search by screening the full text, titles and, in some cases, abstracts, of the literatures. The agreement rate between them was 0.90 , showing a strong accordance (Landis \& Koch 1977). Before reaching an agreement, any differences were discussed. WoSCC data were converted to txt format and imported into CiteSpace V5.5.R1 SE, 64bit (Drexel University, Philadelphia, PA, USA) and the Online Analysis Platform of Literature Metrology (http://bibliometric.com/) for bibliometric analysis. Each downloaded literature was saved from PubMed as a file in XML format and imported into the Bibliographic Item Co-Occurrence Matrix Builder (BICOMB) (developed by Professor Cui from China Medical University and freely available online) (Cui L LW 2008) for hot spot analysis.

\section{Analysis methods}




\section{Bibliometric analysis}

119 We tried to create "The WoSCC Literature Analysis Report" to summarize publication

120 characteristics, such as journals, authors, countries, institution condition, number of annual

121 publications, $\mathrm{H}$ index, and citation counts. To measure the scientific value of research, we

122 enquired the Journal Citation Reports (JCR) 2018 to obtain the impact factor (IF) and the number

123 of citations, which we regarded as important indicators (Eyre-Walker \& Stoletzki 2013). After

124 evaluating these scientific metrics, it was easy to measure different aspects of the publications

125 including their reputation, production and influence. In our study, we used the Literature

126 Metrology online analysis platform to analyze the annual number of publications and

127 country/region growth tendencies. CiteSpace was used for collaboration network analysis to

128 connect journals, authors, institutions and countries. CiteSpace can also use "time slicing", where

129 you could set "years per slice" to 1 and set "top N per slice" to 50, and the top 50 papers in a 1-

130 year slice would be extracted into a single network. According to the aim of our analysis, we

131 selected different node types with the size representing citation counts or the number of

132 publications. (Chen et al. 2010; Chen \& Technology 2014).

133

134

\section{Co-word biclustering analysis of research hotspots}

BICOMB and Microsoft Excel were utilized to identify the proportion of the frequency permutations of major MeSH terms/MeSH subheading terms in the concerned literature.

In this study, the tendencies of the extremely frequent major MeSH terms/MeSH subheading

139 terms were visually stated. Meanwhile, in order to detect the hot spots of postmenopausal osteoporosis research, biclustering of the chosen publications and extremely frequent major $\mathrm{MeSH}$ terms/MeSH subheading terms was carried out. Biclustering was applied to show the relationship between source literatures and extremely frequent words, and the relationship among extremely frequent words. From BICOMB, a binary matrix with source literatures as the columns and extremely frequent major MeSH terms/MeSH subheading terms as the rows, was structured for further biclustering by means of the software "gCLUTO", version 1.0 (Graphical CLUstering TOolkit, a graphical front-end for the CLUTO data clustering library, developed by Rasmussen, Newman, and Karypis from the University of Minnesota)(K 2014). Based on the literature, the parameters of biclustering in gCLUTO were set, and were suitable for biclustering analysis. I2 was then selected for criterion function, Cosine was chosen for similarity function, and repeated bisection for clustering method. The biclustering result of the matrix of source literatures showed extremely frequent major MeSH terms/MeSH subheading terms displayed by matrix visualization and mountain visualization. In order to identify the appropriate number of clusters, the biclustering with different numbers of clusters was redirected until the matrix visualization and mountain visualization reached the optimal result. With semantic relationships found between major MeSH terms/MeSH subheading terms and the typical source literatures in clusters, the fundamental structure of our research focus on postmenopausal osteoporosis was 156 mapped and established. 
157

158

159

160

161

162

163

164

165

166

167

168

169

170

171

172

173

174

175

176

177

178

179

180

181

182

183

184

185

186

187

188

189

190

191

192

193

194

195

196

197

\section{Results}

\section{Distribution characteristics of literature}

\section{Output of related literature}

In total, 5,247 literatures comprising 4,466 articles and 781 reviews (Fig.1), were involved in this study based on search strategy and inclusion criteria (Jan. 1st, 2013-Dec. 31st, 2017). The trend in the number of annual publications related to postmenopausal osteoporosis from 2013 to 2017 is shown in Fig 2, where you can see the overall trend decreases from 1,071 literatures in 2013 to 1,048 literatures in 2017.

\section{Distribution characteristics of countries/regions and institutions}

All of the literatures on postmenopausal osteoporosis contributed by active authors, based on rough statistics, stemmed from at least 81 different countries. The research findings on postmenopausal osteoporosis in different countries or regions are listed in Fig. 3. So far, the United States (1378) has been the largest contributor to postmenopausal osteoporosis research, followed by China (982), Japan (385), England (375), and Italy (352). In regards to the centrality index, although Spain's scientific research output was not very high, it had the largest influence on other countries (centrality $=0.14$ ), followed by Australia $(0.11)$ and the United States $(0.10)$ (Table 1). The top 10 related research institutions ordered by the number of published papers included the University of California, San Francisco (131), Columbia University (129), Seoul National University (128), Amgen Inc (126), and Yonsei University (125) (Table 1). The postmenopausal osteoporosis research network map was a low-density map (density $=0.0843$ ) (Fig. 4), implying that research groups were relatively dispersed across institutions, and that mutual cooperation still needs to be strengthened. Most centrality indexes were less than 0.15 , demonstrating that the influence of most institutions is still at a low level and the amount of cooperation between institutions is inadequate. An analysis of international cooperation is shown in Fig. 5; the most frequent collaboration was between the United States and China, followed by the US and England.

\section{Most active journals}

A total of 1,162 journals have recently emerged in this field. The 10 most active journals published 1,686 publications on postmenopausal osteoporosis, accounting for $32.13 \%$ of all 5,247 publications. The ranking of the top 10 active journals, which are recognized as the core journals in this field, is shown in Table 2. The top three journals are Osteoporosis International, Bone, and Journal of Bone and Mineral Research, and these three journals make up more than $18.27 \%$ of the entire indexed literatures in this area. Journal of Bone and Mineral Research has the largest IF of 5.711, followed by Journal of Clinical Endocrinology and Metabolism (5.605), 
198

199

200

201

202

203

204

205

206

207

208

209

210

211

212

213

214

215

216

217

218

219

220

221

222

223

224

225

226

227

228

229

230

231

232

233

234

235

236

237

238

Bone (4.36), Osteoporosis International (3.819), and Maturitas (3.654). According to the JCR 2018 standards, the top 10 most active journals were classified as Q1, sorted by the IF of the JCR category to which they belong.

\section{Distribution by author}

Of all 19,615 authors included in this subject, the top 10 most productive authors engaged in related research were ranked by the number of published papers. They included Reginster JY, Cooper C, Kanis JA, Lewiecki EM, Rizzoli R, and Eastell R (Table 3). Among them, Reginster JY, from the Department of Public Health, Epidemiology and Health Economics, University of Liège in the Belgium, ranked first with 62 literatures, followed by Cooper C from Nuffield Department of Orthopaedics, Rheumatology and Musculoskeletal Sciences, University of Oxford in UK with 51 literatures. These two scholars made great achievements and are authorities in the research of postmenopausal osteoporosis. CiteSpace analyzed the information cited by the authors and co-cited authors, visualizing it in a network (Fig. 6 \& 7). Kanis JA, with 1,374 cocitations, ranked first among the top 10 co-cited authors (Table 3), followed by Cummngs SR (991), Black DM (760), and Anonymous (687). These experts conducted a great quantity of research and laid a foundation for the development of the field of postmenopausal osteoporosis. The centrality of the first four authors was more than 0.1, indicating that they had formed an influential core scholar group in the domain of postmenopausal osteoporosis research.

\section{Research hot spots of postmenopausal osteoporosis}

In the literature included, 2,439 major MeSH terms/MeSH subheading terms were computed with an accumulated frequency of 9,372 times. After $\mathrm{H}$ index standard evaluation, with an appearance of more than 36 times, a major MeSH term/MeSH subheading term was defined as being extremely frequent. Thirty-six extremely frequent major MeSH terms/MeSH subheading terms extracted from the included publications with an accumulated percentage of $38.22 \%$ (3582/9372) are displayed in Table 4. Different numbers of clusters were found by biclustering. Mountain visualization and matrix visualization showed the biclustering result of the matrix of source literatures - extremely frequent major MeSH terms/MeSH subheading terms. Mountain visualization and the extremely frequent major $\mathrm{MeSH}$ terms/MeSH subheading terms in each cluster classified into eight clusters are illustrated in Fig. 8. The intention of mountain visualization is to visually show the result of biclustering and the essence of high-dimensional datasets. Fig. 8 displays each cluster as a peak in the 3D landform marked with the cluster number (from 0 to 7 , a total of eight clusters). The information about the associated cluster was reflected by its location on the plane, altitude, color and volume of its peak. When compared to other peaks, the location on the plane is the most informative attribute of a peak. The relative similarity of clusters is represented by the interval between peaks on the plane. The altitude of a peak is often in direct proportion to the internal similarity of the cluster. The internal standard deviation of objects in each cluster is revealed by the color of each peak. Blue means high deviation, while red means low deviation. Finally, the volume of a peak is in direct proportion to 
239 the amount of extremely frequent major MeSH terms/MeSH subheading terms stored within the 240 cluster. Based on the authors' knowledge, a minimum of 30 publications should be contained in 241 each independent cluster and triplet peaks should not appear in the mountain visualization. Fig. 9

242 illustrates the matrix visualization, where the column tags are PMIDs of source literatures, and

243 the row tags are extremely frequent major MeSH terms/MeSH subheading terms, separated on

244 the bottom right of the matrix. The values present in the matrix are graphically represented by 245 colors. The color of each reseau paints the proportional emergence frequency of a major MeSH 246 term/MeSH subheading term in a publication. The cumulatively deeper red indicates greater significance, while the white indicates the significance is closer to none. In Table 5, gCLUTO

248 replumed the rows of the initial matrix so that analogous rows in the same cluster are converged; 249 these clusters are partitioned by black horizontal lines. Thirty-six extremely frequent major $250 \mathrm{MeSH}$ terms/MeSH subheadings terms were clustered into eight clusters in the matrix

251

252

253

254

255

256

257

258

259

260

261

262

263

264

265

266

267

268

269

270

271

272

273

274

275

276

277

visualization. The top layered cluster tree describes the relationships among literatures, and the left layered cluster tree demonstrates the relationships among extremely frequent major $\mathrm{MeSH}$ terms/MeSH subheading terms. Each cluster also shows which of the major MeSH term/MeSH subheading terms exists in matching literatures. A deeper exploration of the typical literatures in each cluster was conducted to discern between and to outline the themes of each cluster.

According to the standards discussed above by the research team, the major MeSH terms/MeSH subheading terms were categorized into eight clusters (Fig. 8). These clusters include:

Genetics-related research on bone metabolisms of postmenopausal osteoporosis (Cluster 0), Adverse effects of diphosphonates (Cluster 1),

Therapeutic treatment of postmenopausal osteoporosis (Cluster 2), Administration and dosage of Clinical therapy drug__ diphosphonates (Cluster 3),

Study on epidemiology and etiology of complications of postmenopausal osteoporosis (Cluster 4),

Physiology and physiopathology of postmenopausal osteoporosis (Cluster 5),

Risk factors associated with bone mineral density (BMD) in the diagnosis of postmenopausal osteoporosis (Cluster 6),

Clinical drug effects of dietary supplements on postmenopausal osteoporosis (Cluster 7),

\section{Discussion}

According to the statistical and quantitative analysis by the Online Analysis Platform of Literature Metrology, software CiteSpace and BICOMB, the research output on postmenopausal osteoporosis has gradually decreased over the past five years. MeSH terms can represent the content of literatures and a great quantity of MeSH terms can map the current research status and trends of the field. According to a qualitative and co-word biclustering analysis by gCLUTO software, similar MeSH terms can be identified and categorized into clusters. This is how the research hot spots on postmenopausal osteoporosis were generated, making the essential knowledge structure and trends in this field able be examined systematically. 
278

279

280

281

282

283

284

285

286

287

288

289

290

291

292

293

294

295

296

297

298

299

300

301

302

303

304

305

306

307

308

309

310

311

312

313

314

315

316

317

Cluster 0 relates to genetic research on bone metabolisms of postmenopausal osteoporosis. Postmenopausal osteoporosis is a common polygenic bone metabolic disease. Genetic factors play an important role in the bone metabolism regulation of postmenopausal osteoporosis. BMD, a crucial risk factor for osteoporosis, is highly genetic with estimates of heritability ranging from 0.5 to 0.9 . To date, several studies have reported that some functional genes, such as CYP11A1 in vitamin $\mathrm{D}$ and estrogen hormone-response pathways, the estrogen receptor $\alpha(\mathrm{ER} \alpha)$ gene, tumor necrosis factor (TNF)- $\alpha$ gene, and TNFSF11, TNFRSF11A in the RANKL/RANK/OPG pathway, are implied to be associated with BMD in postmenopausal osteoporosis (Tu et al. 2015). Exploring different genetic variants underlying the development of osteoporosis would make the early prophylactics of osteoporosis possible, as well as the ability to manage individual-based symptomatic treatment.

Cluster 1 relates to adverse effects of diphosphonates. For the treatment of osteoporosis, the most widely used medications are diphosphonates, which are divided into two groups on the basis of their structures. First generation diphosphonates do not contain nitrogen, while new generation diphosphonates have a nitrogen-containing side chain. This structure has a highaffinity for hydroxyapatite at the bone surface, so diphosphonates can preserve for months or even years. After years of evolution, diphosphonates, which include alendronate (ALN), risedronate sodium, ibandronate sodium (IBN) and zoledronic (ZOL), are more durable and stable. The adverse effects of diphosphonates, however, are unavoidable. The first intravenous dose of diphosphonates like IBN and ZOL may trigger an acute-phase response (APR) where after their first diphosphonate infusion, patients have had fevers and pains. Commonly, these symptoms were transient in duration and mild to moderate in intensity, and according to NSAID, the incidence and intensity of such an APR could be efficiently impeded (Ding et al. 2017). Additionally, the atypical femoral fracture (AFF), an unusual atraumatic or minimal-trauma fracture, has also been reported with increasing frequency in long-term diphosphonate users since the first case reports were published in 2005 (Kim et al. 2015). A unique case of AFF after diphosphonate therapy was discovered in 2014, but the patient had a successful recovery through conservative treatment (Pazianas \& Smith 2014). To summarize, it is essential to assess the possibility of atypical fractures in osteoporotic patients when they complain about lower extremity pain, and to take into account alternative treatments instead of diphosphonates.

Cluster 2 relates to the therapeutic treatment of postmenopausal osteoporosis. Drug therapy for osteoporosis can be divided into antiresorptive agents and anabolic agents. Antiresorptive agents are composed of raloxifene (RAL), diphosphonates, and denosumab. Teriparatide is the only anabolic agent for osteoporosis treatment approved by the Food and Drug Administration. Studies have shown that cortical turnover and cortical bone formation in patients who were either treatment naïve (TN) or had previous ALN therapy increased with 24 months of teriparatide treatment (Ma et al. 2014). In other clinical studies, synergistic effects of combination therapy with an antiresorptive agent and teriparatide have been proposed (Shen et al. 2017). The addition of ALN to ongoing teriparatide treatment, and continuing ALN after teriparatide was stopped may be beneficial for patients in terms of areal and volumetric BMD increase (Muschitz et al. 
318 2014). Furthermore, the treatment of combining teriparatide with diphosphonates has shown 319 faster bony unions and highly improved BMD scores (Cho et al. 2017). Although combination

320

321

322

323

324

325

326

327

328

329

330

331

332

333

334

335

336

337

338

339

340

341

342

343

344

345

346

347

348

349

350

351

352

353

354

355

356

357 therapy has obvious advantages, the best time to start combination therapy should be further studied in order to prevent osteoporotic fractures.

Cluster 3 relates to the administration and dosage of diphosphonates. Diphosphonates as an anti-resorptive agent have been accepted for the treatment and prevention of postmenopausal osteoporosis. However, official guidance on the dosage and the length of treatment is lacking, and the curative effect of diphosphonates is not ideal. First, long-term users with 10 dose years or more of a diphosphonates are rare due to periods of low compliance and gaps, with a discrepancy between the length of treatment and doses taken (Abrahamsen 2013). Second, long-term diphosphonate treatment in postmenopausal women does not impair the response to subsequently administered intravenous pamidronate, suggesting that the inadequate response to long-term diphosphonate treatment is not responsible for treatment failure (Yavropoulou et al. 2013).What's more, over the past decade, several reports have highlighted the increased risk of AFF in patients treated with long-term diphosphonates. On the basis of this recommendation, patients may be advised to stop taking diphosphonates for a while. Total hip BMD declines significantly within 1 year of discontinuing diphosphonates, particularly in lean patients (Xu et al. 2016). Cluster 1 has narrated the side effects of diphosphonates, and additional studies are needed to identify reasonable treatments using diphosphonates.

Cluster 4 relates to the epidemiology and etiology of complications of postmenopausal osteoporosis. The worst complications of postmenopausal osteoporosis are fractures, so the accurate assessment and prediction for the risk of fractures are particularly crucial. DXA had been regarded worldwide as the gold standard for the diagnosis of osteoporosis at the lumbar spine and hip, but BMD reveals only a portion of an individual's fracture risk because of the multi-factor fragility fracture. Additionally, to identify patients with a high risk of fracture, many clinical risk factors must be taken into consideration as well as BMD, increasing the possibility of osteoporotic fractures for high-risky patients. The Fracture Risk Assessment Tool (FRAX), uses nine clinical risk factors to predict an individual 10-year risk of major or hip osteoporotic fractures: age, sex, BMI, prior fragility fracture history, family history of hip fracture, the existence of secondary osteoporosis, exposure to systemic glucocorticoids, current smoking and three or more units of alcohol per day. In addition, the International Osteoporosis Foundation (IOF) One Minute Test, though with the lowest predicting rate when compared to other tested tools, has shown competent prediction precision (Briot et al. 2013; Kharroubi et al. 2017). Moreover, there is an increased risk for hip fracture in postmenopausal women with type 2 diabetes (Dytfeld \& Michalak 2017). Further etiology studies should be conducted to prevent the occurrence of the complications discussed above.

Cluster 5 relates to the physiology and physiopathology of postmenopausal osteoporosis. A strong correlation between BMD scores and the probability of fragility fractures has been welldocumented. BMD is affected by multiple factors. Higher BMI scores and moderate levels of physical activity have been found significant in avoiding a decline of BMD (Wee et al. 2013). 
358

359

360

361

362

363

364

365

366

367

368

369

370

371

372

373

374

375

376

377

378

379

380

381

382

383

384

385

386

387

388

389

390

391

392

393

394

395

396

397

Life satisfaction and BMD improvement are longitudinally linked with reduced bone loss in postmenopausal women (Rauma et al. 2014).

Cluster 6 relates to risk factors associated with BMD in the diagnosis of postmenopausal osteoporosis. With the increasing incidence of postmenopausal osteoporosis, it is important to identify risk factors associated with BMD for the prevention of postmenopausal osteoporosis. As there are many factors causing postmenopausal osteoporosis, it is difficult to accurately pinpoint its risk factors. Exercise is consistently effective in (initially) favorably affecting BMD in earlypostmenopausal women without any leveling-off effect after 16 years of exercise (Kemmler et al. 2016). Duration of fertility (years of menstruation) longer than 33 years and a BMI greater than 32 seem to prevent postmenopausal osteoporosis. Age is also an independent risk factor for postmenopausal osteoporosis (Cavkaytar et al. 2015). When it comes to diagnostic imaging, probabilistic sensitivity analysis, DXA and quantitative CT at 55 years-old with quantitative CT screening every 5 years was the best strategy. Furthermore, a combined assessment of bone strength and BMD is a cost-effective strategy for osteoporosis screening in postmenopausal women and has the potential to prevent a large number of osteoporosis fractures.

Cluster 7 relates to the drug effect of alternative therapy - dietary supplements. Pharmacotherapy, diphosphonates for instance, has been widely used to alleviate the risk of fractures and remedy osteoporosis. With low compliance and related adverse effects associated with long-term medication, it is crucial to develop new alternative medicine to treat osteoporosis. Additionally, many people desire alternative and supplemental therapies. A calcium collagen chelate (CC) dietary supplement has shown to be effective in improving BMD and blood biomarkers of bone turnover in osteopenic postmenopausal women (Castelo-Branco 2015; Elam et al. 2015). Context Eucommiae Cortex and Radix Dipsaci, occurring in a ratio of 1:1 in DuZhong-Wan (DZW) and Puerarin 600-O-xyloside, also achieved the same effect as above on ovariectomy mice (Li et al. 2016a; Li et al. 2016b). These have provided new ways to treat patients with osteoporosis.

Nonetheless, we realize several latent limitations in this study. First, although co-word biclustering, based on extremely frequent $\mathrm{MeSH}$ terms, is a highly beneficial way to determine research hot spots in a field, the number of MeSH terms might have some effect on the biclustering analysis results (although the updated emerging themes with low attention may not have been involved). Second, the database updates research continuously, so there may be a discrepancy between bibliometric analysis data and real study conditions, and the number of PMOP papers may grow rapidly with future research breakthroughs.

\section{Conclusions}

Our study found etiology and medication as key points in postmenopausal osteoporosis research. Epidemiology studies developed BMD and FRAX to predict the individual risk of osteoporotic fracture, to summarize high-risk factors associated with PMOP, and to discern between key genes or microenvironmental factors related to PMOP. All these studies laid the 
398 foundation of basic research, especially in terms of genetics. Another hot field is drug treatment.

399

400

401

402

403

404

405

406

407

408

409

410

411

412

413

414

415

416

417

418

419

420

421

422

423

424

425

426

427

428

429

430

431

432

433

434

435

436

437

438

439

440

441

442

443

444
After many years of randomized controlled trials (RCT), current anti-osteoclastogenesis drugs and their side effects have been surveyed and evaluated in detail. Teriparatide and some novel medicines with higher efficacy in promoting osteogenesis should be paid more attention from experts and scholars, and dietary supplements would actually be excellent substitutes for drugs because of their accessibility and low toxicity. The aforementioned hot spots might see great scientific breakthroughs in the near future, and our research might reflect a new direction for postmenopausal osteoporosis research.

\section{References}

Abrahamsen B. 2013. Are long-term bisphosphonate users a reality? Dose years for current bisphosphonate users assessed using the danish national prescription database. Osteoporos Int 24:369-372. 10.1007/s00198-012-1994-x

Bae HW, Rho S, Lee HS, Lee N, Hong S, Seong GJ, Sung KR, and Kim CY. 2014. Hierarchical cluster analysis of progression patterns in open-angle glaucoma patients with medical treatment. Invest Ophthalmol Vis Sci 55:3231-3236. 10.1167/iovs.13-13856

Biglu MH, Ghavami M, and Biglu S. 2014. Authorship, institutional and citation metrics for publications on postmenopausal osteoporosis. Osteoporos Int 25:1337-1343.

Boytsov N, Zhang X, Sugihara T, Taylor K, and Swindle R. 2015. Osteoporotic fractures and associated hospitalizations among patients treated with teriparatide compared to a matched cohort of patients not treated with teriparatide. Curr Med Res Opin 31:1665-1675. 10.1185/03007995.2015.1066765

Briot K, Paternotte S, Kolta S, Eastell R, Felsenberg D, Reid DM, Gluer CC, and Roux C. 2013. FRAX(R): prediction of major osteoporotic fractures in women from the general population: the OPUS study. PLoS One 8:e83436. 10.1371/journal.pone.0083436

Castelo-Branco C. 2015. Calcium-collagen chelate supplementation reduces bone loss in osteopenic postmenopausal women. Climacteric 18:105-106.

Cavkaytar S, Seval MM, Atak Z, Findik RB, Ture S, and Kokanali D. 2015. Effect of reproductive history, lactation, first pregnancy age and dietary habits on bone mineral density in natural postmenopausal women. Aging Clin Exp Res 27:689-694. 10.1007/s40520-015-0333-4

Chen C, Fidelia Ibekwelogan-Juan, Hou J. 2010. The structure and dynamics of cocitation clusters: A multiple-perspective cocitation analysis. J Am Soc Inf Sci Tec 61:7. 10.1002/asi.21309.

Chen C. 2014. CiteSpace II: Detecting and visualizing emerging trends and transient patterns in scientific literature. J Am Soc Inf Sci Tec 57:359-377._10.1002/asi.20317

Cheng Y, and Church GM. 2000. Biclustering of expression data. Proc Int Conf Intell Syst Mol Biol 8:93103.

Cho PG, Ji GY, Shin DA, Ha Y, Yoon DH, and Kim KN. 2017. An effect comparison of teriparatide and bisphosphonate on posterior lumbar interbody fusion in patients with osteoporosis: a prospective cohort study and preliminary data. Eur Spine J 26:691-697. 10.1007/s00586-015-4342-y

Cui L LW YL, Zhang H, Hou YF, Huang YN. 2008. Development of a text mining system based on the co-occurrence of bibliographic items in literature. New Tech of Lib Inf Serv 8:70-75.

Ding Y, Zeng JC, Yin F, Zhang CL, Zhang Y, Li SX, Liu X, Zhang C, Xue QY, Lin H, and Pei FX. 2017. Multicenter Study on Observation of Acute-phase Responses After Infusion of Zoledronic Acid 5 mg in Chinese Women with Postmenopausal Osteoporosis. Orthop Surg 9:284-289.

$10.1111 /$ os. 12338

PeerJ reviewing PDF | (2019:07:39912:2:0:REVIEW 15 Oct 2019) 
445

446

447

448

449

450

451

452

453

454

455

456

457

458

459

460

461

462

463

464

465

466

467

468

469

470

471

472

473

474

475

476

477

478

479

480

481

482

483

484

485

486

487

488

489

490

491

492

493

494

495

Dytfeld J, and Michalak M. 2017. Type 2 diabetes and risk of low-energy fractures in postmenopausal women: meta-analysis of observational studies. Aging Clin Exp Res 29:301-309. 10.1007/s40520016-0562-1

Elam ML, Johnson SA, Hooshmand S, Feresin RG, Payton ME, Gu J, and Arjmandi BH. 2015. A calcium-collagen chelate dietary supplement attenuates bone loss in postmenopausal women with osteopenia: a randomized controlled trial. J Med Food 18:324-331. 10.1089/jmf.2014.0100

Eyre-Walker A, and Stoletzki N. 2013. The assessment of science: the relative merits of post-publication review, the impact factor, and the number of citations. PLoS Biol 11:e1001675. 10.1371/journal.pbio.1001675

Fiannaca A, La Rosa M, La Paglia L, Rizzo R, and Urso A. 2015. Analysis of miRNA expression profiles in breast cancer using biclustering. BMC Bioinformatics 16 Suppl 4:S7. 10.1186/1471-2105-16s4-s7

Hong Y, Yao Q, Yang Y, Feng JJ, Wu SD, Ji WX, Yao L, and Liu ZY. 2016. Knowledge structure and theme trends analysis on general practitioner research: A Co-word perspective. BMC Fam Pract 17:10. 10.1186/s12875-016-0403-5

K L. 2014. gCLUTO-Graphical Clustering Toolkit URL: http://glaros.dtc.umn.edu/gkhome/cluto/gcluto/download. .

Kemmler W, Engelke K, and von Stengel S. 2016. Long-term exercise and bone mineral density changes in postmenopausal women: are there periods of reduced effectiveness? J Bone Miner Res 31:215222. $10.1002 / \mathrm{jbmr} .2608$

Kharroubi A, Saba E, Ghannam I, and Darwish H. 2017. Evaluation of the validity of osteoporosis and fracture risk assessment tools (IOF One Minute Test, SCORE, and FRAX) in postmenopausal Palestinian women. Arch Osteoporos 12:6. 10.1007/s11657-016-0298-8

Kim HS, Jung HY, Kim MO, Joa KL, Kim YJ, Kwon SY, and Kim CH. 2015. Successful conservative treatment: multiple atypical fractures in osteoporotic patients after bisphosphate medication: a unique case report. Medicine (Baltimore) 94:e446. 10.1097/md.0000000000000446

Lahuerta C, Guirola JA, Esteban E, Urbano J, Laborda A, and De Gregorio MA. 2017. Spanish society of vascular and interventional radiology (SERVEI) bibliometric study (2010-2015): what, how, and where do Spanish interventional radiologists publish? Cardiovasc Intervent Radiol 40:1052-1061. 10.1007/s00270-017-1598-0

Landis JR, and Koch GG. 1977. The measurement of observer agreement for categorical data. Biometrics 33:159-174.

Li F, Li M, Guan P, Ma S, and Cui L. 2015. Mapping publication trends and identifying hot spots of research on Internet health information seeking behavior: a quantitative and co-word biclustering analysis. J Med Internet Res 17:e81. 10.2196/jmir.3326

Li F, Yang X, Bi J, Yang Z, and Zhang C. 2016a. Antiosteoporotic activity of Du-Zhong-Wan water extract in ovariectomized rats. Pharm Biol 54:1857-1864. 10.3109/13880209.2015.1133657

Li H, Chen B, Pang G, Chen J, Xie J, and Huang H. 2016b. Anti-osteoporotic activity of puerarin 6"-Oxyloside on ovariectomized mice and its potential mechanism. Pharm Biol 54:111-117. 10.3109/13880209.2015.1017885

Ma YL, Zeng QQ, Chiang AY, Burr D, Li J, Dobnig H, Fahrleitner-Pammer A, Michalska D, Marin F, Pavo I, and Stepan JJ. 2014. Effects of teriparatide on cortical histomorphometric variables in postmenopausal women with or without prior alendronate treatment. Bone 59:139-147. 10.1016/j.bone.2013.11.011

McClung MR, San Martin J, Miller PD, Civitelli R, Bandeira F, Omizo M, Donley DW, Dalsky GP, and Eriksen EF. 2005. Opposite bone remodeling effects of teriparatide and alendronate in increasing bone mass. Arch Intern Med 165:1762-1768. 10.1001/archinte.165.15.1762

Muschitz C, Kocijan R, Fahrleitner-Pammer A, Pavo I, Haschka J, Schima W, Kapiotis S, and Resch H. 2014. Overlapping and continued alendronate or raloxifene administration in patients on teriparatide: effects on areal and volumetric bone mineral density--the CONFORS Study. $J$ Bone Miner Res 29:1777-1785. 10.1002/jbmr.2216

Peer] reviewing PDF | (2019:07:39912:2:0:REVIEW 15 Oct 2019) 
496

497

498

499

500

501

502

503

504

505

506

507

508

509

510

511

512

513

514

515

516

517

518

519

520

521

522

523

524

525

526

527

528

529

530

531

532

533

534

535

536

537

538

539

540

541

542

543

544

545

546

Oncken C, Prestwood K, Kleppinger A, Wang Y, Cooney J, and Raisz L. 2006. Impact of smoking cessation on bone mineral density in postmenopausal women. $J$ Womens Health (Larchmt) 15:1141-1150. 10.1089/jwh.2006.15.1141

Pazianas M, and Smith R. 2014. Commentary: drug-associated atypical femoral fractures (DaAFFs): balancing the facts. $J$ Clin Endocrinol Metab 99:2340-2342. 10.1210/jc.2014-1375

Pluskiewicz W, Drozdzowska B, Adamczyk P, and Noga K. 2018. Scientific output quality of 40 globally top-ranked medical researchers in the field of osteoporosis. Archives of Osteoporosis 13:35. 10.1007/s11657-018-0446-4

Rauma PH, Koivumaa-Honkanen H, Williams LJ, Tuppurainen MT, Kroger HP, and Honkanen RJ. 2014. Life satisfaction and bone mineral density among postmenopausal women: cross-sectional and longitudinal associations. Psychosom Med 76:709-715. 10.1097/psy.0000000000000114

Schwartz AV, Nevitt MC, Brown BW, Jr., and Kelsey JL. 2005. Increased falling as a risk factor for fracture among older women: the study of osteoporotic fractures. Am J Epidemiol 161:180-185. 10.1093/aje/kwi023

Shen Y, Gray DL, and Martinez DS. 2017. Combined pharmacologic therapy in postmenopausal osteoporosis. Endocrinol Metab Clin North Am 46:193-206. 10.1016/j.ecl.2016.09.008

Tu P, Duan P, Zhang RS, Xu DB, Wang Y, Wu HP, Liu YH, and Si L. 2015. Polymorphisms in genes in the RANKL/RANK/OPG pathway are associated with bone mineral density at different skeletal sites in post-menopausal women. Osteoporos Int 26:179-185. 10.1007/s00198-014-2854-7

Wee J, Sng BY, Shen L, Lim CT, Singh G, and Das De S. 2013. The relationship between body mass index and physical activity levels in relation to bone mineral density in premenopausal and postmenopausal women. Arch Osteoporos 8:162. 10.1007/s11657-013-0162-z

Wu Q, Zhong ZM, Pan Y, Zeng JH, Zheng S, Zhu SY, and Chen JT. 2015. Advanced oxidation protein products as a novel marker of oxidative stress in postmenopausal osteoporosis. Med Sci Monit 21:2428-2432. 10.12659/msm.894347

Xu LH, Adams-Huet B, Poindexter JR, and Maalouf NM. 2016. Determinants of change in bone mineral density and fracture risk during bisphosphonate holiday. Osteoporos Int 27:1701-1708. 10.1007/s00198-015-3447-9

Yavropoulou MP, Hamdy NA, and Papapoulos SE. 2013. Long-term treatment of osteoporotic women with bisphosphonates does not impair the response to subsequently administered intravenous pamidronate. Osteoporos Int 24:2353-2357. 10.1007/s00198-013-2301-1

Zhao F, Shi B, Liu R, Zhou W, Shi D, and Zhang J. 2018. Theme trends and knowledge structure on choroidal neovascularization: a quantitative and co-word analysis. BMC Ophthalmol 18:86. 10.1186/s12886-018-0752-z

Zheng HF, Forgetta V, Hsu YH, Estrada K, Rosello-Diez A, Leo PJ, Dahia CL, Park-Min KH, Tobias JH, Kooperberg C, Kleinman A, Styrkarsdottir U, Liu CT, Uggla C, Evans DS, Nielson CM, Walter K, Pettersson-Kymmer U, McCarthy S, Eriksson J, Kwan T, Jhamai M, Trajanoska K, Memari Y, Min J, Huang J, Danecek P, Wilmot B, Li R, Chou WC, Mokry LE, Moayyeri A, Claussnitzer M, Cheng CH, Cheung W, Medina-Gomez C, Ge B, Chen SH, Choi K, Oei L, Fraser J, Kraaij R, Hibbs MA, Gregson CL, Paquette D, Hofman A, Wibom C, Tranah GJ, Marshall M, Gardiner BB, Cremin K, Auer P, Hsu L, Ring S, Tung JY, Thorleifsson G, Enneman AW, van Schoor NM, de Groot LC, van der Velde N, Melin B, Kemp JP, Christiansen C, Sayers A, Zhou Y, Calderari S, van Rooij J, Carlson C, Peters U, Berlivet S, Dostie J, Uitterlinden AG, Williams SR, Farber C, Grinberg D, LaCroix AZ, Haessler J, Chasman DI, Giulianini F, Rose LM, Ridker PM, Eisman JA, Nguyen TV, Center JR, Nogues X, Garcia-Giralt N, Launer LL, Gudnason V, Mellstrom D, Vandenput L, Amin N, van Duijn CM, Karlsson MK, Ljunggren O, Svensson O, Hallmans G, Rousseau F, Giroux S, Bussiere J, Arp PP, Koromani F, Prince RL, Lewis JR, Langdahl BL, Hermann AP, Jensen JE, Kaptoge S, Khaw KT, Reeve J, Formosa MM, XuerebAnastasi A, Akesson K, McGuigan FE, Garg G, Olmos JM, Zarrabeitia MT, Riancho JA, Ralston SH, Alonso N, Jiang X, Goltzman D, Pastinen T, Grundberg E, Gauguier D, Orwoll ES, Karasik D, Davey-Smith G, Consortium A, Smith AV, Siggeirsdottir K, Harris TB, Zillikens MC, van

Peer] reviewing PDF | (2019:07:39912:2:0:REVIEW 15 Oct 2019) 
547

548

549

550

551

552

553
Meurs JB, Thorsteinsdottir U, Maurano MT, Timpson NJ, Soranzo N, Durbin R, Wilson SG, Ntzani EE, Brown MA, Stefansson K, Hinds DA, Spector T, Cupples LA, Ohlsson C, Greenwood CM, Consortium UK, Jackson RD, Rowe DW, Loomis CA, Evans DM, Ackert-Bicknell CL, Joyner AL, Duncan EL, Kiel DP, Rivadeneira F, and Richards JB. 2015. Whole-genome sequencing identifies EN1 as a determinant of bone density and fracture. Nature 526:112-117. 10.1038 /nature 14878 
Figure 1

Flow chart of literature filtering included in this study.

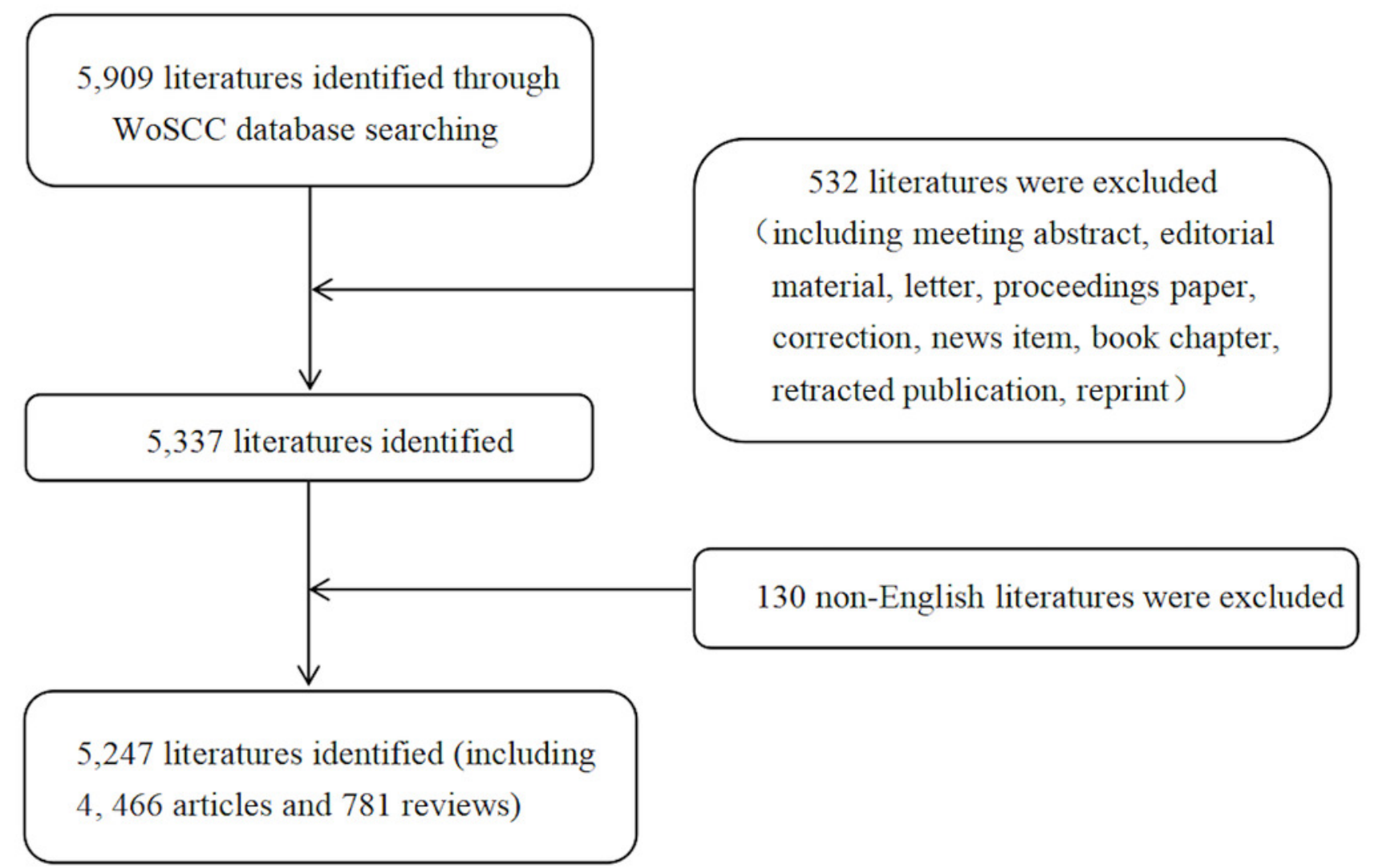


Figure 2

Output of related literature. The number of annual publications in postmenopausal osteoporosis from 2013 to 2017.

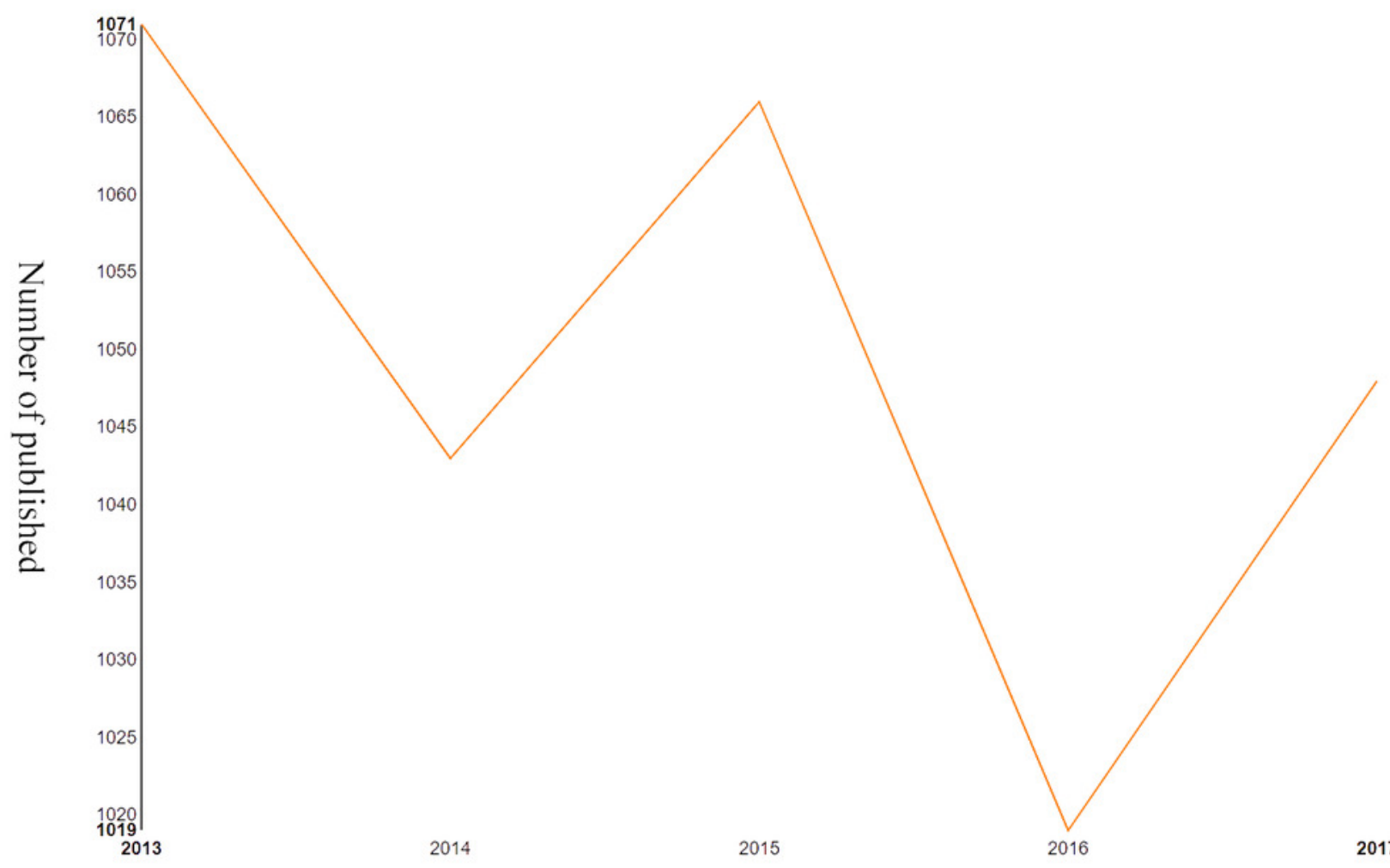

Publication Year 


\section{Figure 3}

Output of related literature. The growth trends of the top 10 countries/regions in postmenopausal osteoporosis from 2013 to 2017.

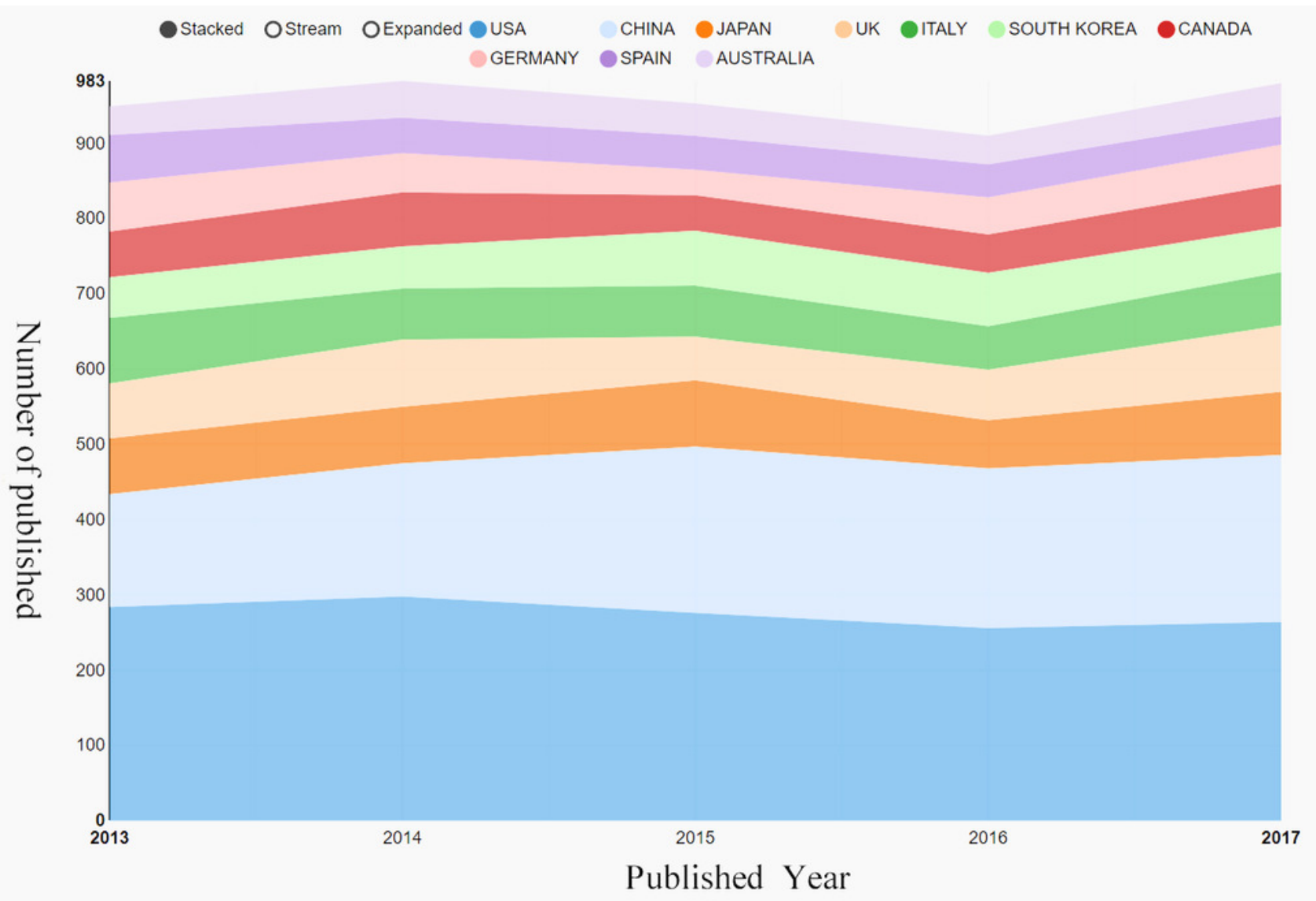


Figure 4

The distribution of countries/regions and institutions. The network map of institutions that involved in postmenopausal osteoporosis research.

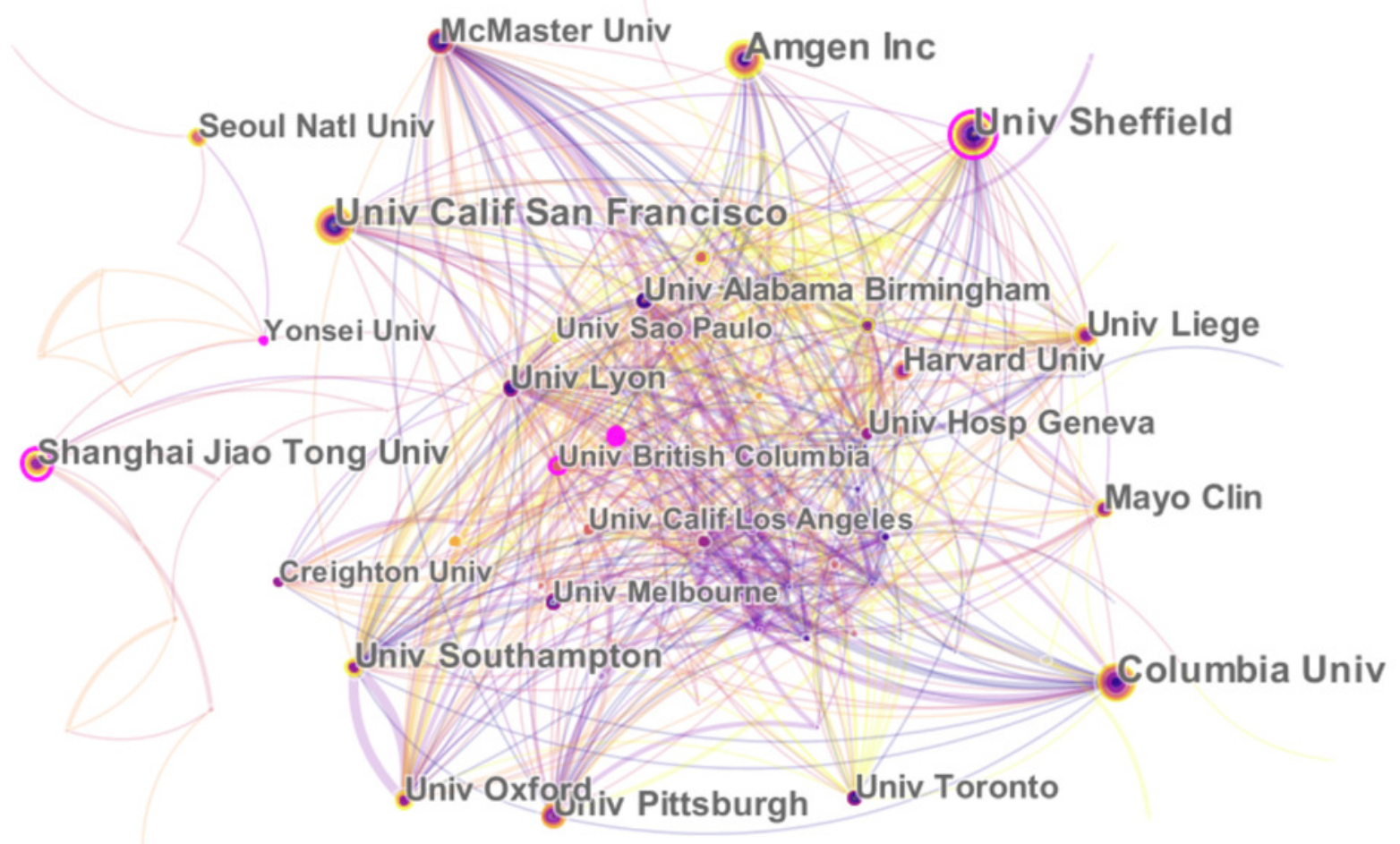


Figure 5

The distribution of countries/regions and institutions. The cooperation of countries/regions that involved in postmenopausal osteoporosis research.

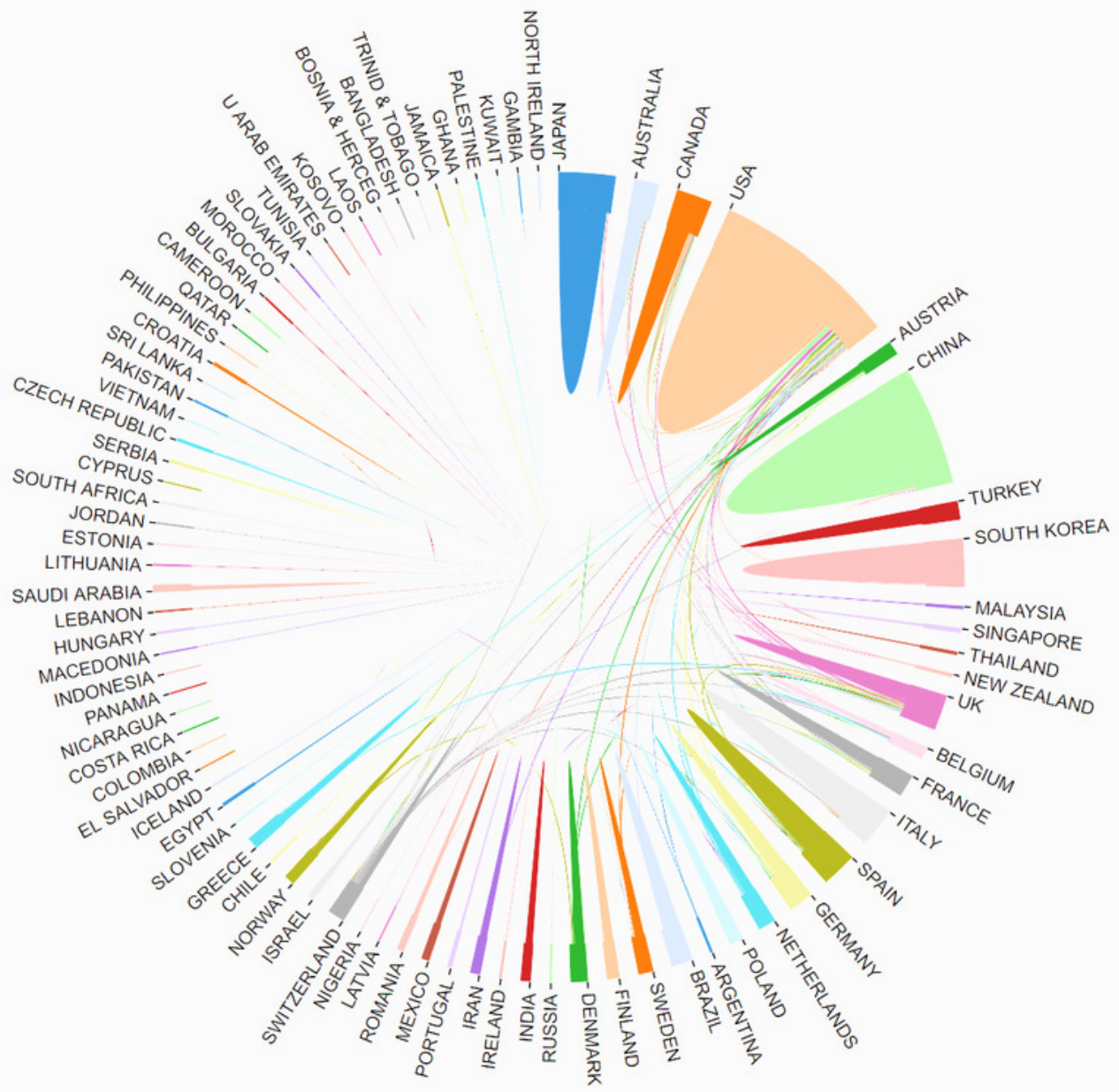


Figure 6

The distribution of authors engaged in postmenopausal osteoporosis research. The network map of productive authors.

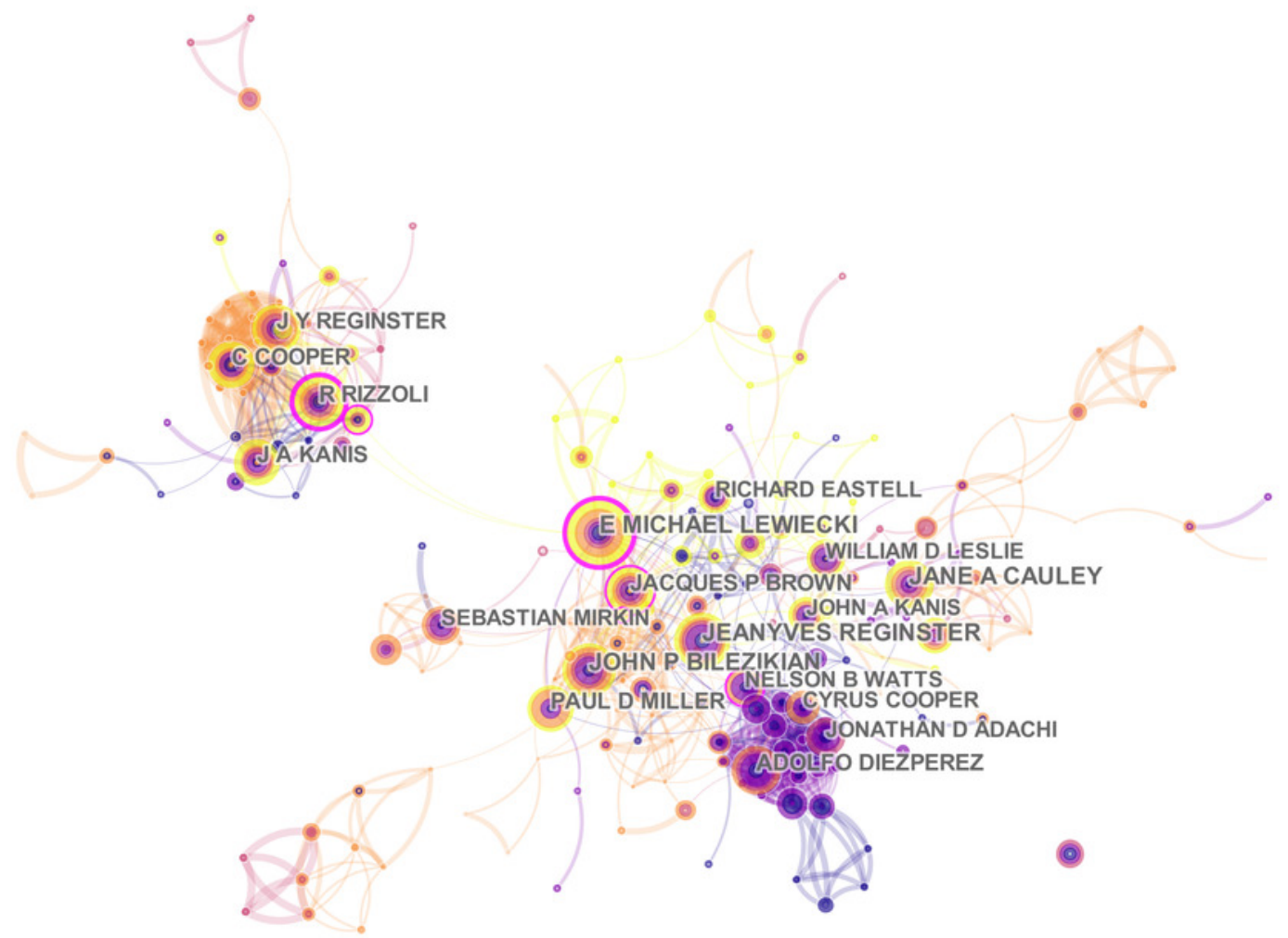




\section{Figure 7}

The distribution of authors engaged in postmenopausal osteoporosis research. The network map of co-cited authors.

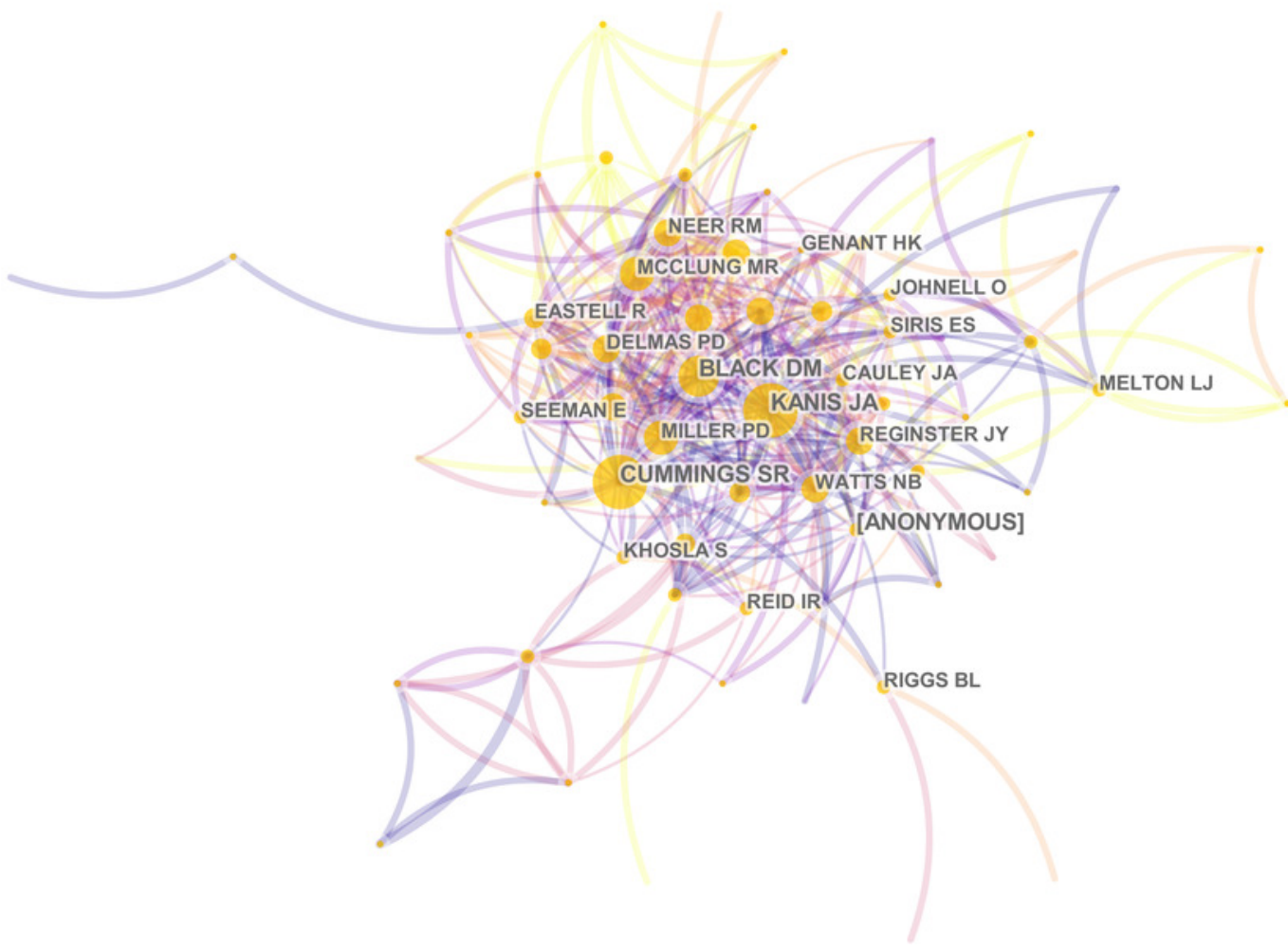




\section{Figure 8}

Mountain visualization of biclustering of highly frequent major MeSH terms and articles on postmenopausal osteoporosis
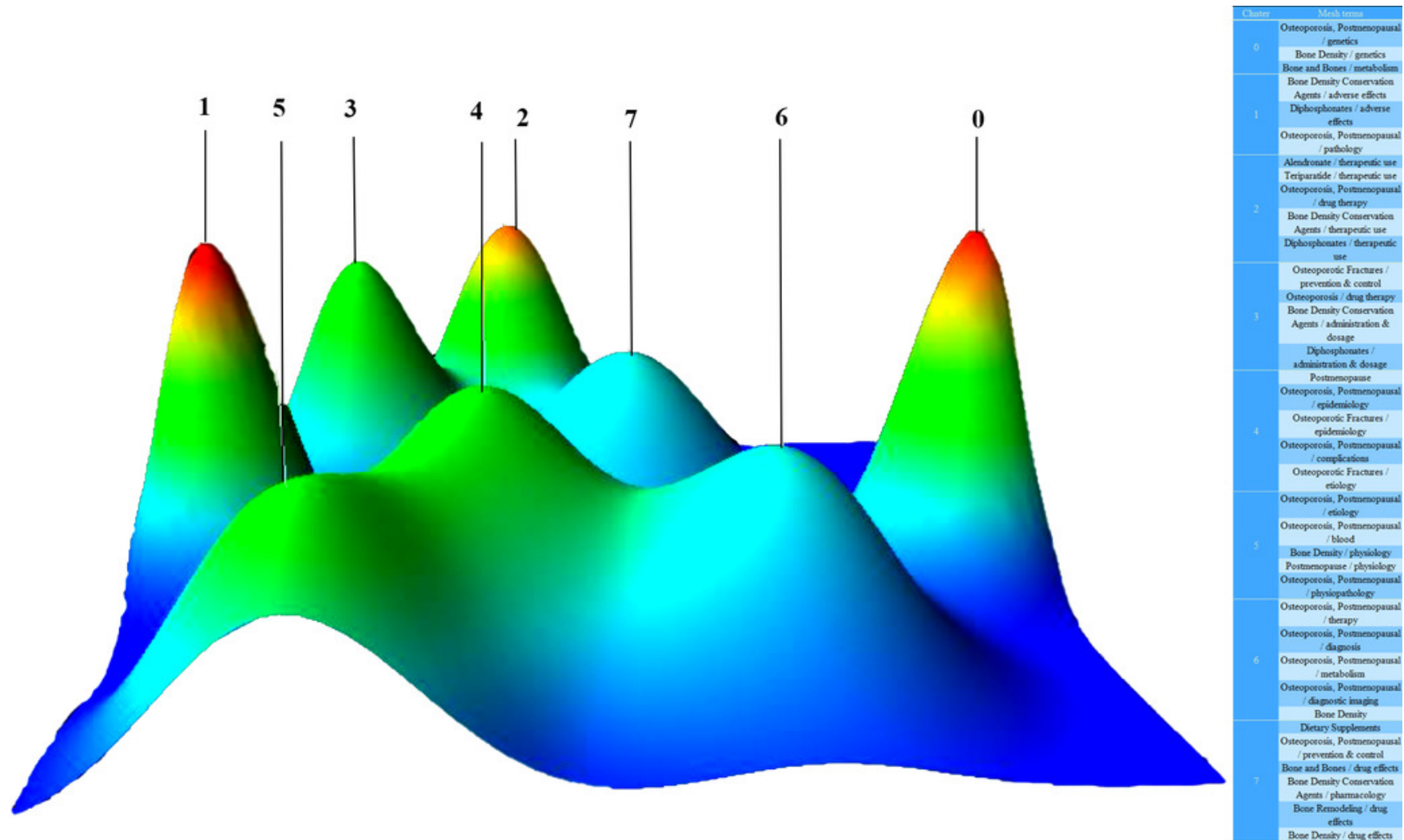
Figure 9

Visualized matrix of biclustering of highly frequent major MeSH terms and PubMed Unique Identifiers (PMIDs) of articles on postmenopausal osteoporosis.

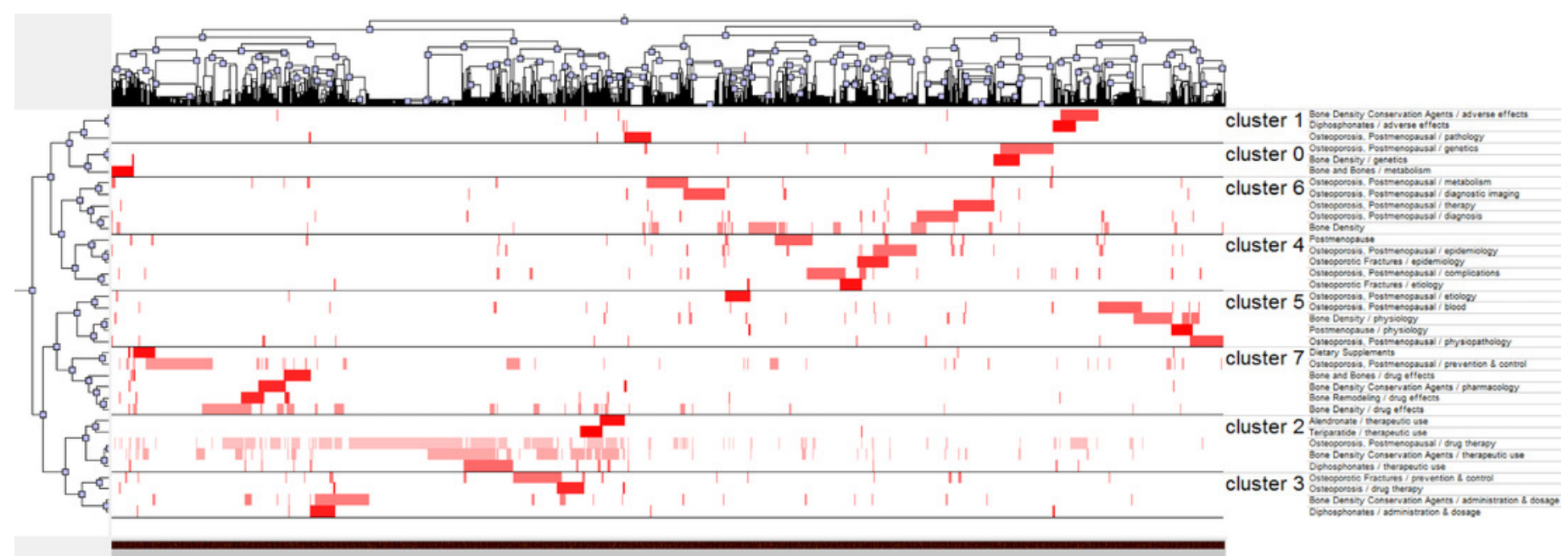




\section{Table $\mathbf{1}$ (on next page)}

The top 10 countries/regions and institutions contributing to publications in postmenopausal osteoporosis research. 


\begin{tabular}{|c|c|c|c|c|c|c|c|c|c|c|c|}
\hline Rank & Country/Region & $\begin{array}{l}\text { Article } \\
\text { Counts }\end{array}$ & Centrality & Institutions & $\begin{array}{l}\text { Article } \\
\text { Counts }\end{array}$ & Centrality & $\begin{array}{c}\text { Total } \\
\text { number } \\
\text { of } \\
\text { citations }\end{array}$ & $\begin{array}{c}\text { Average } \\
\text { number } \\
\text { of } \\
\text { citations }\end{array}$ & $\begin{array}{c}\text { Total } \\
\text { number } \\
\text { of first } \\
\text { authors }\end{array}$ & $\begin{array}{l}\text { Total } \\
\text { number } \\
\text { of first } \\
\text { author } \\
\text { citations }\end{array}$ & $\begin{array}{c}\text { Average } \\
\text { number } \\
\text { of first } \\
\text { author } \\
\text { citations }\end{array}$ \\
\hline 1 & US & 1378 & 0.10 & $\begin{array}{l}\text { Univ Calif San } \\
\text { Francisco }\end{array}$ & 131 & 0.08 & 1133 & 8.65 & 30 & 294 & 9.8 \\
\hline 2 & $\begin{array}{c}\text { People's Republic } \\
\text { of China }\end{array}$ & 982 & 0.00 & Columbia Univ & 129 & 0.04 & 957 & 7.42 & 39 & 338 & 8.67 \\
\hline 3 & Japan & 385 & 0.00 & Seoul Natl Univ & 128 & 0.03 & 203 & 1.59 & 35 & 72 & 2.06 \\
\hline 4 & England & 375 & 0.02 & Amgen Inc & 126 & 0.05 & 1087 & 8.63 & 18 & 110 & 6.11 \\
\hline 5 & Italy & 352 & 0.01 & Yonsei Univ & 125 & 0.15 & 172 & 1.38 & 30 & 33 & 1.1 \\
\hline 6 & South Korea & 314 & 0.00 & Mayo Clin & 123 & 0.02 & 487 & 3.96 & 30 & 92 & 3.07 \\
\hline 7 & Canada & 288 & 0.02 & Univ Sheffield & 115 & 0.16 & 1398 & 12.16 & 33 & 170 & 5.15 \\
\hline 8 & Germany & 252 & 0.02 & $\begin{array}{c}\text { Shanghai Jiao Tong } \\
\text { Univ }\end{array}$ & 112 & 0.15 & 141 & 1.26 & 55 & 74 & 1.35 \\
\hline 9 & Spain & 237 & 0.14 & Univ Toronto & 101 & 0.02 & 284 & 2.81 & 18 & 56 & 3.11 \\
\hline 10 & Australia & 212 & 0.11 & Univ Liege & 93 & 0.02 & 1145 & 12.31 & 28 & 97 & 3.46 \\
\hline
\end{tabular}




\section{Table 2 (on next page)}

The top 10 most active journals that published articles in postmenopausal osteoporosis research (sorted by count). 


\begin{tabular}{|c|c|c|c|c|c|c|c|c|}
\hline Rank & Journal title & $\begin{array}{l}\text { Article } \\
\text { Counts }\end{array}$ & $\begin{array}{l}\text { Percentage } \\
(\mathrm{N} / 5,247)\end{array}$ & $\begin{array}{c}\text { IF } \\
(2018)\end{array}$ & $\begin{array}{l}\text { Quartile } \\
\text { in } \\
\text { category } \\
(2018)\end{array}$ & $\mathrm{H}$-index & $\begin{array}{c}\text { Total } \\
\text { number } \\
\text { of } \\
\text { citations }\end{array}$ & $\begin{array}{c}\text { Average } \\
\text { number } \\
\text { of } \\
\text { citations }\end{array}$ \\
\hline 1 & OSTEOPOROSIS INTERNATIONAL & 497 & $9.47 \%$ & 3.819 & Q1 & 157 & 2175 & 4.38 \\
\hline 2 & BONE & 238 & $4.54 \%$ & 4.36 & Q1 & 183 & 964 & 4.05 \\
\hline 3 & JOURNAL OF BONE AND MINERAL RESEARCH & 224 & $4.27 \%$ & 5.711 & Q1 & 223 & 1690 & 7.54 \\
\hline 4 & CALCIFIED TISSUE INTERNATIONAL & 123 & $2.34 \%$ & 3.265 & Q1 & 106 & 332 & 2.7 \\
\hline 5 & JOURNAL OF BONE AND MINERAL METABOLISM & 121 & $2.31 \%$ & 2.31 & Q1 & 66 & 218 & 1.8 \\
\hline 6 & PLOS ONE & 120 & $2.29 \%$ & 2.776 & Q1 & 176 & 179 & 1.49 \\
\hline 7 & JOURNAL OF CLINICAL ENDOCRINOLOGY \& METABOLISM & 115 & $2.19 \%$ & 5.605 & Q1 & 98 & 778 & 6.77 \\
\hline 8 & JOURNAL OF CLINICAL DENSITOMETRY & 86 & $1.64 \%$ & 2.184 & Q1 & 29 & 232 & 2.7 \\
\hline 9 & MATURITAS & 81 & $1.54 \%$ & 3.654 & Q1 & 91 & 291 & 3.59 \\
\hline 10 & $\begin{array}{l}\text { MENOPAUSE-THE JOURNAL OF THE NORTH AMERICAN } \\
\text { MENOPAUSE SOCIETY }\end{array}$ & 81 & $1.54 \%$ & 2.942 & Q1 & 93 & 189 & 2.33 \\
\hline
\end{tabular}




\section{Table 3(on next page)}

The top 10 most productive authors and co-cited authors contributed to publications in postmenopausal osteoporosis research. 


\begin{tabular}{|c|c|c|c|c|c|c|c|c|c|c|c|c|c|}
\hline Rank & Author & $\begin{array}{l}\text { Article } \\
\text { Counts }\end{array}$ & Centrality & $\begin{array}{c}\text { Total } \\
\text { number } \\
\text { of } \\
\text { citations }\end{array}$ & $\begin{array}{c}\text { Average } \\
\text { number } \\
\text { of } \\
\text { citations }\end{array}$ & $\begin{array}{l}\text { First } \\
\text { author } \\
\text { counts }\end{array}$ & $\begin{array}{l}\text { First } \\
\text { author } \\
\text { citation } \\
\text { counts }\end{array}$ & $\begin{array}{l}\text { Average } \\
\text { first } \\
\text { author } \\
\text { citation } \\
\text { counts }\end{array}$ & $\begin{array}{c}\text { Corresponding } \\
\text { author }\end{array}$ & $\begin{array}{c}\text { Corresponding } \\
\text { author citation } \\
\text { counts }\end{array}$ & $\begin{array}{l}\text { Co-cited } \\
\text { author }\end{array}$ & $\begin{array}{l}\text { Citation } \\
\text { counts }\end{array}$ & Centrality \\
\hline 1 & $\begin{array}{l}\text { Reginster, } \\
\text { JY }\end{array}$ & 62 & 0.01 & 810 & 13.06 & 10 & 57 & 5.7 & 13 & 75 & Kanis JA & 1374 & 0.37 \\
\hline 2 & Cooper, C & 51 & 0.00 & 660 & 12.94 & 1 & 13 & 13 & 11 & 75 & $\begin{array}{c}\text { Cummngs } \\
\text { SR }\end{array}$ & 991 & 0.27 \\
\hline 3 & Kanis, JA & 46 & 0.02 & 841 & 18.28 & 7 & 256 & 36.57 & 11 & 279 & Black DM & 760 & 0.16 \\
\hline 4 & $\begin{array}{l}\text { Lewiecki, } \\
\text { EM }\end{array}$ & 44 & 0.38 & 505 & 11.48 & 10 & 45 & 4.5 & 19 & 74 & Anonymous & 687 & 0.02 \\
\hline 5 & Rizzoli, R & 42 & 0.22 & 456 & 10.86 & 10 & 102 & 10.2 & 13 & 117 & Johnell O & 534 & 0.02 \\
\hline 6 & Eastell, R & 39 & 0.07 & 280 & 7.18 & 5 & 29 & 5.8 & 7 & 37 & Mcclung MR & 507 & 0.08 \\
\hline 7 & Adachi, JD & 38 & 0.03 & 181 & 4.76 & 1 & 1 & 1 & 1 & 1 & Khosla S & 483 & 0.01 \\
\hline 8 & Lee, SH & 38 & 0.00 & 90 & 2.37 & 5 & 8 & 1.6 & 7 & 33 & Reginster, JY & 449 & 0.04 \\
\hline 9 & Brandi, ML & 37 & 0.11 & 368 & 9.95 & 2 & 3 & 1.5 & 11 & 16 & Rjggs BL & 438 & 0.10 \\
\hline 10 & Miller, PD & 36 & 0.00 & 306 & 8.5 & 9 & 80 & 8.89 & 10 & 96 & Reid IR & 428 & 0.03 \\
\hline
\end{tabular}




\section{Table 4 (on next page)}

Highly frequent major $\mathrm{MeSH}^{1}$ terms from the included publications on postmenopausal osteoporosis $(n=9372)$. 


\begin{tabular}{|c|c|c|c|c|}
\hline Rank & Major MeSH terms/ MeSH subheadings & Frequency & $\begin{array}{l}\text { Proportion } \\
\text { of } \\
\text { frequency } \\
\text { (\%) }\end{array}$ & $\begin{array}{c}\text { Cumulative } \\
\text { percentage } \\
\text { (\%) }\end{array}$ \\
\hline 1 & Osteoporosis, Postmenopausal / drug therapy & 577 & 6.1566 & 6.1566 \\
\hline 2 & Bone Density Conservation Agents / therapeutic use & 305 & 3.2544 & 9.411 \\
\hline 3 & Osteoporosis, Postmenopausal / prevention \& control & 208 & 2.2194 & 11.6304 \\
\hline 4 & Bone Density / drug effects & 185 & 1.974 & 13.6044 \\
\hline 5 & Bone Density & 172 & 1.8353 & 15.4396 \\
\hline 6 & $\begin{array}{l}\text { Bone Density Conservation Agents / administration \& } \\
\text { dosage }\end{array}$ & 135 & 1.4405 & 16.8801 \\
\hline 7 & Bone Density / physiology & 116 & 1.2377 & 18.1178 \\
\hline 8 & Osteoporotic Fractures / prevention \& control & 113 & 1.2057 & 19.3235 \\
\hline 9 & Osteoporosis, Postmenopausal / epidemiology & 110 & 1.1737 & 20.4972 \\
\hline 10 & Osteoporosis, Postmenopausal / complications & 104 & 1.1097 & 21.6069 \\
\hline 11 & Diphosphonates / therapeutic use & 102 & 1.0883 & 22.6953 \\
\hline 12 & Osteoporosis, Postmenopausal / genetics & 96 & 1.0243 & 23.7196 \\
\hline 13 & Osteoporosis, Postmenopausal / diagnosis & 94 & 1.003 & 24.7226 \\
\hline 14 & Osteoporosis, Postmenopausal / metabolism & 94 & 1.003 & 25.7256 \\
\hline 15 & Postmenopause & 92 & 0.9816 & 26.7072 \\
\hline 16 & Osteoporosis, Postmenopausal / blood & 91 & 0.971 & 27.6782 \\
\hline 17 & Osteoporosis, Postmenopausal / diagnostic imaging & 80 & 0.8536 & 28.5318 \\
\hline 18 & Osteoporosis, Postmenopausal / physiopathology & 72 & 0.7682 & 29.3 \\
\hline 19 & Osteoporosis, Postmenopausal / therapy & 68 & 0.7256 & 30.0256 \\
\hline 20 & Bone Density Conservation Agents / adverse effects & 67 & 0.7149 & 30.7405 \\
\hline 21 & Osteoporotic Fractures / epidemiology & 53 & 0.5655 & 31.306 \\
\hline 22 & Bone Remodeling / drug effects & 51 & 0.5442 & 31.8502 \\
\hline 23 & Bone Density Conservation Agents / pharmacology & 50 & 0.5335 & 32.3837 \\
\hline 24 & Osteoporosis / drug therapy & 50 & 0.5335 & 32.9172 \\
\hline 25 & Bone and Bones / drug effects & 48 & 0.5122 & 33.4294 \\
\hline 26 & Osteoporosis, Postmenopausal / pathology & 47 & 0.5015 & 33.9309 \\
\hline 27 & Diphosphonates / administration \& dosage & 46 & 0.4908 & 34.4217 \\
\hline 28 & Osteoporosis, Postmenopausal / etiology & 43 & 0.4588 & 34.8805 \\
\hline 29 & Bone Density / genetics & 43 & 0.4588 & 35.3393 \\
\hline 30 & Osteoporotic Fractures / etiology & 41 & 0.4375 & 35.7768 \\
\hline 31 & Dietary Supplements & 40 & 0.4268 & 36.2036 \\
\hline
\end{tabular}




\begin{tabular}{|l|cccc}
\hline 32 & Alendronate / therapeutic use & 40 & 0.4268 & 36.6304 \\
\hline 33 & Diphosphonates / adverse effects & 39 & 0.4161 & 37.0465 \\
\hline 34 & Postmenopause / physiology & 37 & 0.3948 & 37.4413 \\
\hline 35 & Bone and Bones / metabolism & 37 & 0.3948 & 37.8361 \\
\hline 36 & Teriparatide / therapeutic use & 36 & 0.3841 & 38.2202 \\
\hline
\end{tabular}

1 


\section{Table 5 (on next page)}

Highly frequent major MeSH a terms-source articles matrix (localized). 


\section{PeerJ}

\begin{tabular}{|c|c|c|c|c|c|c|}
\hline No. & Major MeSH terms/ MeSH subheadings & \multicolumn{5}{|c|}{ Pubmed Unique Identifiers of source articles } \\
\hline$\square$ & $\square$ & 21631599 & 22057139 & 22302614 & $\ldots$ & 29782125 \\
\hline 1 & Osteoporosis, Postmenopausal / drug therapy & 0 & 0 & 0 & $\ldots$ & 0 \\
\hline 2 & Bone Density Conservation Agents / therapeutic use & 0 & 0 & 0 & $\ldots$ & 0 \\
\hline 3 & Osteoporosis, Postmenopausal / prevention \& control & 1 & 0 & 1 & $\ldots$ & 0 \\
\hline 4 & Bone Density / drug effects & 0 & 0 & 1 & $\ldots$ & 0 \\
\hline$\ldots$ & $\ldots$ & ... & $\ldots$ & $\ldots$ & $\ldots$ & $\ldots$ \\
\hline 35 & Bone and Bones / metabolism & 0 & 0 & 0 & $\ldots$ & 0 \\
\hline 36 & Teriparatide / therapeutic use & 0 & 0 & 0 & $\ldots$ & 0 \\
\hline
\end{tabular}

